бавосир дар 14 бемор пайдо шуд ва онхо зергуруухи аввалро ташкил доданд.Ба зергурӯхи дуюм 33 нафар беморони НХМ дар якчоягй бо пролапси узвхои таносул (ректоселе -13, цистоцеле-5, пролапси бачадон (пурра ва нопурра) - 8, ректоселе ва цистоцеле дар якчоягй - 7) дохил карда шуданд. Беморон дар ин зергурӯх аз бисёр таваллудкунандагон ва занони пиронсол иборат буданд. Хангоми норасоихои махбал, мушакхои коси хурд бо зарари халка мушак, дарачаи кашишхуррии боқимондахои мушакхои халкаро ва дарачаи денервацияи наххои қисми берунии он, инчунин мушакхои коси хурд, ахамияти калон доштанд.Ба зергурӯхи сеюм 11 нафар беморони НХМ дар якчоягй бо равандхои пиоинфламатсионй (фистулаи ректовагиналй -5 , фистулаи ligature -4 , фистулаи параректалии қаблй -2) дохил карда шуданд.
Ба зергурӯхи 45 нафара беморони НХМ дар якчоягй бо ду ва ё зиёда омилхои этиологии шакли омехтаи беморй дохил карда шуданд.

Хулоса. Тахлили чараёни клиникии НХМ дар занон нишон дод, ки омилхои марбут ба гендер дар 51,8\% холатхо ба рушди шакли омехтаи беморй мусоидат кардаанд. Усулхои тадқиқоти функсионалии гузаронидашуда нишон доданд, ки дар баробари халка мушакхои берунй ва дохилии руддаи рост, мушакхои пубо-ректалй дар беморони НХМ зарар мебинанд, ки инро хангоми интихоби усулхои табобат барои шакли омехтаи НХМ бояд ба назар гирифт.

Калимахои калидй:халка мушак, норасогии халка мушак, даридани чатан баъд аз таваллуд, шақли омехтаи норасогии халка мушак.

А.М. Наимов ${ }^{1,2}$, А.А. Раззоков ${ }^{3}$

ДИАГНОСТИКА СИНДРОМА ЖИРОВОЙ ЭМБОЛИИ ПРИ СОЧЕТАННОЙ ТРАВМЕ

\author{
'Таджикский институт профилактической медицины \\ ${ }^{2}$ Национальный медицинский центр «Шифобахи» \\ ${ }^{3}$ Кафедра травматологии, ортопеди и ВПХ, ТГМУ им. Абуали ибни Сино
}

Наимов Абдукарим Мамадрахимович - соискатель Таджикского института профилактической медииины, заведующий отделением экстренной травматологии и сочетанной травмы Начионального медицинского иентра «Шифобахш» Республики Таджикистан, Душанбе, пр. И. Сомони 59; Тел.: (+992)918888822; E-mail: abdukarim.naimov@bk.ru

Цель исследования. Совершенствование диагностики синдрома жировой эмболии (СЖЭ) у больных с сочетанной травмой.

Материал и методы исследования. В 2014-2020 годы пролечены 250 больных с сочетанной травмой в возрасте от 18 до 60 лет. Мужчин было 174 (69,6\%), женщин - 76 (30,4\%). Больные распределялись на две группы, основная группа - 128 (51,2\%) больных с сочетанной травмой, у которых диагностика, профилактики и лечение СЖЭ проводилось совершенствованными подходами, контрольная группа 122 (48,8\%) больных с сочетанной травмой, у которых диагностика, профилактика и лечение СЖЭ проводилось традиционными подходами.

Результаты исследования и их обсуждение. На основе комплексного анализа данных с формализацией и стандартизаиией данных путем сравнения частоты симптомов в группе больных с и без СЖЭ выявлены интегральные критерии для диагностики различных клинических проявлений данного симптомокомплекса. На основе полученных данных разработан высокоэффективный метод диагностики СЖЭ. В основной группе дифференцированное лечение больных с применением разработанных подходов способствовало увеличению удельного веса хороших результатов $(43,7 \%)$ и снижению неудовлетворительных результатов (8.6\%) и летальности $(8,6 \%)$. В контрольной группе преобладали удовлетворительные (36.0\%) и неудовлетворительные результаты $(15,6 \%)$ и летальные исходы $(16,4 \%)$.

Выводы. Применение совериенствованных подходов к диагностике СЖЭ и построение лечебной тактики на этой основе относится к эффективным путям улучшения результатов сочетанной травмы.

Ключевые слова, алгоритм диагностики синдрома жировой эмболии (СЖЭ), сочетанная травма, синдром жировой эмболии, жировая глобуллемия. 


\title{
THE DIAGNOSTICS OF FAT EMBOLISM SYNDROME AT MULTITRAUMA
}

\author{
${ }^{1}$ Tajik Institute of Preventive Medicine \\ 2"Shifobakhsh" the National Medical Center \\ ${ }^{3}$ Department of Traumatology, Orthopedics and Military Field Surgery of Avicenna Tajik State Medical University, \\ Dushanbe, Tajikistan
}

Naimov Abdukarim Mamadrahimovich - Candidate of the Tajik Institute of Preventive Medicine, Head of the Department of Emergency Traumatology and combined trauma of the National Medical Center «Shifobakhsh» of the Republic of Tajikistan, 59 I. Somoni Ave., Dushanbe; Tel.: (+992)9188888222; E-mail: abdukarim.naimov@bk.ru

Aim. To improve diagnostics of fat embolism syndrome in patients with multitrauma.

Material and methods. The study included 250 patients with multitrauma at the age of 18 to 60 years that received treatment during 2014-2010. There were 174 (69.6\%) men and 76 (30.4\%) women. The patients were divided into two groups. The main group included $128(51,2 \%)$ patients with multitrauma, in whom the diagnosis, prevention, and treatment of fat embolism syndrome were carried out using improved approaches. The control group of 122 (48, 8\%) patients with multitrauma received a diagnosis, prevention, and treatment of fat embolism syndrome using traditional approaches.

Results and methods. Comprehensive analysis of data with the formalization and standardization of data by comparing the frequency of symptoms in the group of patients with and without fat embolism syndrome helped to reveal integral criteria for the diagnosis of various clinical manifestations of this symptom-complex were identified. Based on the data obtained, a highly effective method for the diagnosis of fat embolism syndrome has been developed. In the main group, differentiated treatment of patients using the developed approaches contributed to an increase in the proportion of positive results (43.7\%) and a decrease in unsatisfactory results $(8.6 \%)$ and mortality $(8.6 \%)$. In the control group, satisfactory (36.0\%) and unsatisfactory results (15.6\%), as well as lethal outcomes (16.4\%), prevailed.

Conclusion. The use of improved approaches in the diagnosis and treatment of fat embolism syndrome and the construction of treatment tactics on this basis are among the effective ways to improve the results of multitrauma.

Keywords, The algorithm for diagnosing fat embolism syndrome, multitrauma, fat embolism syndrome, fat globullemia.

Актуальность. В настоящее время травматизм и связанные с ним проблемы превратились к числу актуальных медико-социальных задач, что связано с увеличением удельного веса травматизма в структуре заболеваемости, высокой частотой инвалидности, осложнений и летальности $[1,8,11$, 14]. Среди актуальных задач острого периода сочетанной и множественной травмы особо следует выделить вопросы диагностики и лечения синдрома жировой эмболии (СЖЭ) при множественных и сочетанных травмах. Последние наблюдаются в $17,5-28,0 \%$ и среди них в $49,8 \%-83,5 \%$ случаях встречаются повреждения конечностей. Последние рассматриваются как причина развития СЖЭ. Удельный вес СЖЭ травматического генеза колеблется от $0,5 \%-10 \%$ до $90 \%$ [4, 3, 9], что, повидимому, объясняется различной структурой исследуемых выборок по характеру и тяжести травм. Летальность при СЖЭ колеблется от 53\% - 67\% до $3 \%-15 \%[7,10]$.

Вопросы диагностики СЖЭ относятся к числу наиболее актуальных среди всего комплекса задач острого периода сочетанной травмы $[2,5,6,13,1$
2]. Это обусловлено сложностью диагностики, малоосвещенностью данной проблемы, а также отсутствием объективных критериев диагностики СЖЭ на фоне других проявлений острого периода сочетанной травмы [2]. В литературе объективная диагностика СЖЭ многими исследователями рассматривается как один из инструментов улучшения результатов сочетанной травмы, т.к. на основании этих данных строится оптимальная тактики лечения обсуждаемых повреждений $[5,6,12]$. В свете вышеприведенных данных становится очевидным необходимость разработки оптимальных методов диагностики СЖЭ, чему посвящена настоящая работа.

Цель исследования. Улучшение результатов комплексного лечения сочетанной травмы путем совершенствования диагностики СЖЭ.

Материалы и методы исследования. Работа основана на комплексном анализе данных 250 больных с сочетанной травмой, пролеченных в 2014-2020 годы в отделении сочетанной травмы Национального медицинского центра «Шифобахш» Республики Таджикистан. Возраст боль- 
ных колебался от 18 до 60 лет, медиана возраста - 45,6士1.8 лет. Мужчин было 174 (69,6\%), женщин - 76 (30,4\%). В 198 (79,2\%) случаях наблюдались ДТП (59,2\%) и кататравма (20,0\%), отличающиеся возникновением наиболее тяжелых повреждений.

В зависимости от предпринятой тактики диагностики СЖЭ больные распределялись на две группы: основная группа - 128 (51,2\%) больных с сочетанной травмой, у которых диагностика СЖЭ проводилась совершенствованными подходами; контрольная группа -122 (48,8\%) больных с сочетанной травмой, у которых диагностика СЖЭ проводилась традиционными подходами.

В ходе выполнения настоящей работы использовались клинические критерии, рентгенография органов и систем, КТ и МРТ по показаниям, лабораторные (экспресс-метод определения жировой глобуллемии по Корнилову, а также определение показателей красной крови, тромбоцитов, коагулограммы) и статистические методы исследования. Дыхательную недостаточность определяли клиническими методами, уровень сознания - по шкале комы Глазго. При СЖЭ эти симптомы считались положительными при любой степени этих нарушений.

Статистическая обработка материала проведена с использованием пакета прикладных программ Statistica 10,0 (Statsoft, США).

Результаты исследования и их обсуждение. В первые трое суток после травмы СЖЭ $(\mathrm{n}=125)$ развилось у 15 (12\%) больных, в 4-5 сутки - у $26(20,8 \%)$, в 6-7 сутки - у $29(23,2 \%)$ и в сроки более 7 суток - у 55 (44,0\%) пациентов. Наиболее тяжелые проявления СЖЭ наблюдались в первую неделю после травмы., в течение которого должна проводится превентивная, активная и целенаправленная диагностика СЖЭ.

В ходе выполнения настоящей работы мы придерживались общепринятой градации симптомов СЖЭ на «большие» (петихии, нарушение дыхания и сознания) и «малые» (симптом Пурчера, «снежная буря» при рентгенографии, гипертермия, желтуха, нарушение психики, тахикардия, анемия, тромбоцитопения, гиперкоагуляция, пневмония). Сочетание трех больших симптомов с жировой глобуллемией, независимо от других проявлений СЖЭ и сочетанной травмы, трактовалось как классическая форма СЖЭ. Петихии относятся к патогомоничным признакам этой формы СЖЭ, т.к. при других формах СЖЭ они не встречались. Нарушение сознания протекало в виде комы, имело более длительный характер (до 30 и более дней). Во всех случаях дыхательная недостаточность протекала на фоне тяжелой гипоксии. При классической форме СЖЭ частота встречаемости «малых» симптомов колебалась от $8,3 \%$ до 79,2\%, в среднем на одного больного приходится сочетание до 4,5 «малых» симптомов. К наиболее характерным проявлениям классической формы СЖЭ относится максимально короткий промежуток времени между эмболией малого и большого круга кровообращения. Классическая форма СЖЭ наблюдалась у 24 (9,6\%) больных.

Клиническая форма СЖЭ выставлялась при сочетании нарушения сознания и дыхания или одного из них с «малыми» симптомами, включая обязательный положительный лабораторный тест на жировую глобуллемию. Обязательным условием для включения больных в эту форму СЖЭ также явилось отсутствие доказанной связи нарушения сознания и/или дыхания с соответствующими травмами черепа и грудной клетки. Последнее обстоятельство предусматривает выполнение по показаниям диагностических процедур (рентгенография, КТ, МРТ), направленных на выяснение причинно-следственной связи нарушения сознания и дыхания с травмой черепа и груди. При клинической форме нарушение сознания и дыхания протекали как в тяжелом, так и в легком варианте. Сроки регресса клинико-лабораторных проявлений СЖЭ в среднем составляют до 2-3 недель. Частота встречаемости различных «малых» симптомов колеблется от $8,6 \%$ до $68,0 \%$, на одного больного приходится до 4,5 «малых» симптомов. Данная форма СЖЭ установлена у 35 (14,0\%) больных.

Субклиническая форма СЖЭ установлена у 66 (26,4\%) больных при наличии жировой глобуллемии и «малых» симптомов в различных сочетаниях. Основными объективными причинами выделения субклинической формы СЖЭ являются устойчивое и характерное сочетание «малых» признаков в различных комбинациях, сочетание с жировой глобуллемией, совпадение сроков развития и регресса «малых» признаков со аналогичными показателями жировой глобуллемии, более позднее (после недели от начала травмы) появление признаков, более короткие (в среднем до одной недели) сроки регресса клинических проявлений и жировой глобуллемии, переход в клиническую или классическую форму при выборе неадекватной тактики лечения,с очетание с жировой глобуллемией II или III степени и отсутствие летальных исходов.

Течение СЖЭ при сочетанной травме от- 
Таблица 1

Частота симптомов при различных клинических формах СЖЭ

\begin{tabular}{|c|c|c|c|c|c|c|c|c|}
\hline \multirow{3}{*}{ Наименование симптомов СЖЭ } & \multicolumn{6}{|c|}{ Клинические формы СЖЭ } & \multirow{2}{*}{\multicolumn{2}{|c|}{$\begin{array}{c}\text { Всего } \\
(\mathrm{n}=125)\end{array}$}} \\
\hline & \multicolumn{2}{|c|}{ класс. $(\mathrm{n}=24)$} & \multicolumn{2}{|c|}{ клин $(\mathrm{n}=35)$} & \multicolumn{2}{|c|}{ субкл. $(\mathrm{n}=66)$} & & \\
\hline & абс., & в \% & абс., & в \% & aбc., & в \% & абс., & в \% \\
\hline Петихии & 24 & 100,0 & - & - & - & - & 24 & 100,0 \\
\hline Нарушение дыхания & 24 & 100,0 & 21 & 60,0 & - & - & 45 & 36,0 \\
\hline Нарушение сознания & 24 & 100,0 & 25 & 71,4 & - & - & 49 & 39,2 \\
\hline Симптом Пурчера & 14 & 58,3 & 15 & 42,9 & 23 & 34,8 & 52 & 41,6 \\
\hline «Снежная буря» при рентгенографии & 11 & 45,8 & 12 & 34,3 & 16 & 24,2 & 39 & 31,2 \\
\hline Гипертермия & 9 & 37,5 & 14 & 40,0 & 25 & 37,8 & 48 & 38,4 \\
\hline Желтуха & 2 & 8,3 & 3 & 8,6 & 6 & 9,1 & 11 & 8,8 \\
\hline Нарушение психики & 3 & 12,5 & 11 & 31,4 & 12 & 18,2 & 26 & 20,8 \\
\hline Тахикардия & 19 & 79,2 & 26 & 74,3 & 51 & 77,3 & 96 & 76,8 \\
\hline Анемия & 17 & 70,8 & 24 & 68,6 & 49 & 74,2 & 90 & 72,0 \\
\hline Тромбоцитопения & 9 & 37,5 & 12 & 34,3 & 25 & 37,8 & 46 & 36,8 \\
\hline Гиперкоагуляция & 15 & 62,5 & 23 & 67,5 & 28 & 42,4 & 66 & 52,8 \\
\hline Пневмония & 9 & 37,5 & 16 & 45,7 & 36 & 54,5 & 61 & 48,8 \\
\hline
\end{tabular}

Примечание: «большие» симптомы выделены жирным шрифтом.

Таблица 2

Шкала для диагностики СЖЭ

\begin{tabular}{|c|c|c|}
\hline Критерии & Значения & Балл \\
\hline \multirow{2}{*}{ Петихии } & нет & 0 \\
\hline & есть & 9 \\
\hline \multirow{3}{*}{ Нарушение сознания } & ясное & 0 \\
\hline & сопор & 2 \\
\hline & кома & 5 \\
\hline \multirow{2}{*}{ Дыхательная недостаточность } & нет & 0 \\
\hline & есть & 5 \\
\hline \multirow{2}{*}{ Симптом Пурчера } & нет & 0 \\
\hline & есть & 2 \\
\hline \multirow{2}{*}{ Нарушение психики } & нет & 0 \\
\hline & есть & 2 \\
\hline \multirow{2}{*}{ Желтуха } & нет & 0 \\
\hline & есть & 2 \\
\hline \multirow{2}{*}{ Гипертермия более 38 градусов } & нет & 0 \\
\hline & есть & 2 \\
\hline \multirow{2}{*}{ Тахикардия } & нет & 0 \\
\hline & есть & 2 \\
\hline \multirow{2}{*}{ Симптом «снежной бури» при рентгенографии легких } & нет & 0 \\
\hline & есть & 2 \\
\hline \multirow{5}{*}{ Жировая глобуллемия } & 1 степень & 1 \\
\hline & 2 степень & 2 \\
\hline & 3 степень & 5 \\
\hline & 4 степень & 9 \\
\hline & отрицательная & 0 \\
\hline \multirow{2}{*}{ Внезапное снижение гематокрита (менее 28 об.\%) } & нет & 0 \\
\hline & есть & 2 \\
\hline \multirow{2}{*}{ Снижение числа тромбоцитов менее 160x10 /л } & нет & 0 \\
\hline & есть & 2 \\
\hline \multirow{2}{*}{ Гиперкоагуляция } & нет & 0 \\
\hline & есть & 2 \\
\hline \multirow{2}{*}{ Повышение подфасциального давления } & нет & 0 \\
\hline & есть & 3 \\
\hline
\end{tabular}


личалось выраженным полиморфизмом, о чем свидительствует частота клинических симптомов обсуждаемого симптомокомплекса при различных его клинических формах (табл. 1).

На основании результатов исследования предложена усовершенствования экспресс-шкала для диагностики СЖЭ. Данная шкала разработана на основе анализа статистических данных о частоте симптомов и присуждения на этой основе интегральным признакам СЖЭ определенного балла методом экспертных оценок (табл. 2).

Перед тестированием также с помощью метода экспертных оценок определяли баллы для каждой клинической формы СЖЭ, жировой глобуллемии, а также при отсутствии клинических и лабораторных проявлений СЖЭ. При сумме баллов более 25 выставлялась классическая форма, от 15 до 24 - клиническая форма, от 5 до 14 - субклиническая форма, от 2 до 5 - жировая глобулемия и ниже 2 баллов исключались СЖЭ и жировая глобуллемия.

Тестирование предложенной шкалы проводилось ретроспективно с использованием результатов обследования всех 250 больных из обеих групп. Эффективность данной шкалы в целом составила $84,4 \%$, при классической и клинической форме $100,0 \%$, при субклинической форме - 83,4\%, при жировой глобуллемии без клинически проявлений - 80,3\%, при отсутствии СЖЭ и жировой глобуллемии - 75,0\%. Учитывая высокую эффективность реализованной шкалы по сравнению с рекомендующими показателями из литературы (70\%), ее можно рекомендовать для широкого применения в клинической практике. Весомым косвенным аргументом в пользу эффективности предложенной шкалы также являлись результаты изучения отдаленных результатов сочетанной травмы. Так, в основной группе дифференцированное лечение больных с применением разработанных подходов при диагностике СЖЭ и реализация тактики ранней стабилизации нестабильных переломов до развития обсуждаемого симптомокомплекса способствовали увеличению удельного веса хороших результатов $(43,7 \%)$ и снижению неудовлетворительных результатов $(8.6 \%)$ и летальности $(8,6 \%)$. В контрольной группе преобладали удовлетворительные $(36.0 \%)$ и неудовлетворительные результаты (15,6\%), а также летальные исходы $(16,4 \%)$.

Заключение. Применение совершенствованных подходов к диагностике СЖЭ и построение на этой основе лечебной тактики с ранней стабилизацмией нестабильных переломов до развития СЖЭ относятся к эффективным путям улучшения результатов сочетанной травмы.

\section{ЛИТЕРАТУРА (III. 11-16 cM. REFERENCES)}

1. Агаджанян В.В. Госпитальная летальность при политравме и основные направления её снижения. / В.В.Агаджанян [и др.] // Политравма. - 2015. - № 1. -C. $1-15$.

2. Габдуллин М.М. Синдром жировой эмболии. /М.М. Габдуллин, Н.Н.Митракова, Р.Г. Гатиатулин // Современные медицинские технологии. - 2012. - №1. -С. 108-14.

3. Дмитриев А.В. Жировая эмболия, этиология и клиническая диагностика, обзор литературы. /А.В. Дмитриев, А.Е.Доросевич // Вестник образования и развития науки Российской академии естественных наук. - 2016. - №1. - С. 83-8.

4. Калинкин О.Г. Современные представления о синдроме посттравматической жировой эмболии. / О.Г.Калинкин, Е.П.Курапов, Е.И.Гридасова // Таврический медико-биологический вестник. - 2012. -№ 2. -C. 117-20.

5. Радевская Н.С. Профилактика синдрома жировой эмболии при тяжёлых сочетанных травмах. / Н.С.Радевская, Л.В.Овчинников // Евразийский союз учёных. -2015. № 11(20). -С. 159-62.

6. Раззоков А.А. Совершенствование тактики лечения тяжёлой сочетанной черепно-мозговой травмы с учётом клинических проявлений синдрома жировой эмболии / А.А. Раззоков, М.К. Назаров // Вестник Авиценны. 2017. Т. 19. № 3. С. 331-337.

7. Садриев О.Н., Ахмаджонов 3.С. Сочетанные костно-сосудистые повреждения нижних конечностей / О.Н. Садриев, 3.С. Ахмаджонов // Наука молодых (Eruditio Juvenium). 2015. № 1. С. 67-73.

8. Сироджов К.Х. Оптимизированный подход к лечению переломов с учётом нарушений некоторых аспектов липидного спектра у больных с сочетанной черепно-мозговой травмой. / К.Х.Сироджов [и др.] // Уральский медицинский журнал. - 2016. -№ 5. -С. 90-4.

9. Штейнле А.В. Синдром жировой эмболии (аналитический обзор) / А.В. Штейнле // Сибирский медицинский журнал. -2009. - №2. - С. 117-26.

10. Щеколова Н.Б. Анализ летальности, ошибки и осложнения при лечении пострадавших с множественными и сочетанными травмами. / Н.Б. Щеколова, Я.В. Ненахова, Н.С. Зубарева // Уральский медицинский журнал. - 2015. - № 7. - С. 127-31.

\section{REFERENCES}

1. Agadzhanyan V.V. Gospitalnaya letalnost pri politravme i osnovnye napravleniya ee snizheniya [Hospital mortality in polytrauma and the main directions of its reduction]. Politravma -Polytrauma, 2015, No. 1, pp. 1-15.

2. Gabdullin M.M. Sindrom zhirovoy embolii [Fat embolism syndrome]. Sovremennye meditsinskie tekhnologii - Modern medical technologies, 2012, No. 1, pp. 108-114.

3. Dmitriev A.B. Zhirovaya emboliya, etiologiya i 
klinicheskaya diagnostika, obzor literatury [Fat embolism, etiology and clinical diagnosis, literature review]. Vestnik obrazovaniya i razvitiya nauki Rossiyskoy akademii estestvennykh nayk - Bulletin of Education and Science Development of the Russian Academy of Natural Sciences, 2016, No. 1, pp. 83-88.

4. Kalinkin O.G. Sovremennye predstavleniya o syndrome posttravmaticheskoy zhirovoy emboli [Current understanding of post-traumatic fat embolism syndrome]. Tavriticheskiy medico-biologicheskiy vestnik - Tavriticheskiy medico-biologicheskiy vestnik, 2012, No. 2, pp. 117-120.

5. Radevskaya N.S. Profilaktika sindroma zhirovoy embolii pri tyazhelykh sochetannykh travmakh [Prevention of fat embolism syndrome in severe combined injuries]. Evraziyskiy soyuz uchenykh - Eurasian Union of Scientists, 2015. No. 11 (20), pp. 159-162.

6. Razzokov A.A. Sovershenstvovenie taktiki lecheniya tyazheloy sochetannoy cherepno-mozgovoy travmy s uchetom klinicheskikh proyavleniy sindroma zhirovoy emboli [Improvement of treatment tactics of severe combined craniocerebral trauma with regard to clinical manifestations of fat embolism syndrome]. Vestnik Avitsenny - Avicenna Bulleten, 2017, Vol. 19, No. 3, pp. 331-337.

7. Sadriev O.N. Sochetannye kostno-sosudistaye povrezhdeniya nizhnikh konechnostey [Combined bone and vascular injuries of the lower extremities]. Nauka molodyh (Erudito Juvenium) - Science of the young (Eruditio Juvenium), 2015, No. 1, pp. 67-73.

8. Sirodzhov K.K. Optimizirovannyy podkhod k lecheniyu perelomov s uchetom narusheniy nekotorykh aspektov lipidnogo spektra u bolnykh s sochetannoy cherepno-mozgovoy travmoy [Optimized approach to fracture treatment taking into account some aspects of the lipid spectrum in patients with combined craniocerebral trauma]. Uralskiy meditsinskiy zhurnal - Ural Medical Journal, 2016, No. 5, pp. 90-94.

9. Shteynle A.B. Sindrom zhirovoy emboli (analiticheskiy obzor) [Optimized approach to fracture treatment taking into account some aspects of the lipid spectrum in patients with combined craniocerebral trauma]. Sibirskiy meditsinskiy zhurnal - Siberian Medical Journal, 2009, No. 2, pp. 117-126.

10. Shchekolova N.B. Analiz letalnosty, oshibki i oslozhneniya pri lechenii postradavshikh s mnozhestvennymi i sochetannymi travmami [Analysis of mortality, errors and complications in the treatment of patients with multiple and combined injuries]. Uralskiy meditsinskiy zhurnal - Ural Medical Journal, 2015, No. 7, pp. 127-131.

11. Huber-Lang M. An unusual case of early fulminant post-traumatic fat embolism syndrome. Anesthesia, 2005, Vol. 60 (11), pp. 1141-1143.

12. Latif A. Fat embolism and fat embolism syndrome. Professional Medical Journal, 2008, Vol. 15 (4), pp. 407413.

13. Probst C. 30 years of polytrauma care, An analysis of the change in strategies and results of 4849 cases treated at a single institution. Injury, 2009, Vol. 40 (1), pp. 77-83.
14. Shaikh N. Emergency management of fat embolism syndrome. Journal of Emergencies, Trauma, and Shock, 2009, Vol. 2 (1), pp. 29-33.

15. Volpin G. Fat embolism syndrome following injuries and limb fractures. Harefuah, 2010, Vol. 149 (5), pp. 304-335.

16. Wurmb T. Polytrauma management in a period of change, time analysis of new strategies for emergency room treatment. Unfallchirurg, 2009, Vol. 112 (4), pp. 390-399.

\section{ХУЛОСА \\ А.М. Наимов, А.А. Раззоқов \\ ТАШХИСИ СИНДРОМИ ЭМБОЛИЯИ РАВҒАНЙ ХАНГОМИ ОСЕБХОИ ОМЕХТА}

Мақсади тадқиқот. Такмили ташхиси синдроми эмболияи равағанй дар беморон бо осебхои омехта.

Маводхо ва усулхои тадқиқот. Дар солхои 2014-2020 250 бемор бо осеби омехта дар синни аз 18 то 60-сола табобат гирифтанд. 174 мард $(69,6 \%)$, занон - 76 (30,4\%) буданд. Беморон ба ду гурӯх тақсим карда шуданд, гурӯхи асосй - 128 нафар $(51,2 \%)$ беморони гирифтори осеби омехта, ки дар онхо ташхис, пешгирй ва табобати СЭР бо усули бехтаргардонида гузаронида шуданд, гурӯхи назоратй 122 (48,8\%) беморони гирифтори осеби омехта буданд, ки дар онхо ташхис, пешгирй ва табобати СЭР бо истифода аз равишхои анъанавй анчом дода шуд.

Натичахои тахқиқот ва мухокимаи онхо. Дар асоси тахлили хамачонибаи маълумот бо формализатсия ва стандартикунонии маълумот тавассути муқоисаи басомади нишонахо дар гурӯхи беморони гирифтори СЭР ва бидуни меъёрхои интегралии ташхиси нишонахои гуногуни клиникии ин мачмӯи аломатхо муайян карда шуданд. Дар асоси маълумоти бадастомада, усули хеле самараноки ташхиси СЭР тахия шудааст.

Дар гурӯхи асосй табобати дифференсиалии беморон бо истифодаи усулхои тахияшуда ба афзоиши хиссаи натичахои хуб $(43,7 \%)$ ва кохиши натичахои ғайриқаноатбахш $(8,6 \%)$ ва фавт $(8,6 \%)$ мусоидат кард. Дар гурӯхи назорат натичахои қаноатбахш (36,0\%) ва ғайриқаноатбахш $(15,6 \%)$ ва натичахои марговар (16,4\%) бартарй доштанд.

Хулоса. Истифодаи усулхои муосири ташхиси СЭР ва дар замимаи он ташхис намудани методхои табобати замонавй ва бехтар намудани натичахои осеби омехта мусоидат менамояд.

Калимахои калидй: алгоритми ташхиси СЭР, осеби омехта, синдроми эмболияи равғанй, глобулемияи равғанй. 